Western University

Scholarship@Western

Department of Economics Research Reports

Economics Working Papers Archive

1974

\title{
Taxation in a Two-Period Temporal Model of Consumption and Portfolio Allocation
}

Syed M. Ahsan

Follow this and additional works at: https://ir.lib.uwo.ca/economicsresrpt

Part of the Economics Commons

Citation of this paper:

Ahsan, Syed M.. "Taxation in a Two-Period Temporal Model of Consumption and Portfolio Allocation." Department of Economics Research Reports, 7413. London, ON: Department of Economics, University of Western Ontario (1974). 
Research Report 7413

TAXATION IN A TWO-PERIOD TEMPORAL MODEL

OF CONSUMPTION AND PORTFOLIO ALLOCATION

by

Syed M. Ahsan 
TAXATION IN A TWO-PERIOD TEMPORAL MODEL

OF CONSUMPTION AND PORTFOLIO ALLOCATION*

by

\author{
Syed M. Ahsan \\ Department of Economics \\ University of Western Ontario \\ London, Canada N6A 3K7
}

\title{
1. MOTIVATION
}

Although the effects of taxation on risk-taking have been fairly extensively examined in the mean-variance framework, ${ }^{1}$ it is only recently that the effects of taxation have been considered in more general expected utility of wealth models (see, for example, Ahsan (1974b, 1975), Mossin (1968) and Stiglitz (1969a)). However, all these models (both the more recent and the more restrictive mean-variance models) have ignored the consumption-saving decisions. This practice, although analytically convenient, is not a satisfactory description of household decision processes. Certainly the decision to hold one's wealth in varlous forms is closely related to the objective of attaining future consumption plans that enable the individual to attain maximal expected lifetime utility. This view of individual decision-making implies that the discussion of portfolio selection is inseparable from the discussion of optimal consumption decisions under uncertainty. Such an integration of portfolio and consumption decisions allows the individual, by optimally choosing the amount devoted to consumption, to vary the amount of investable wealth. We can, therefore, consider the simultaneous determination of the size and the composition of the optimal portfollo.

Recently several authors have attempted such an integration of portfolio choice and consumption allocation over time. ${ }^{2}$ In light of this development, it is natural to ask whether the effects of taxation on risk-taking depend in any essential way on the assumption of a fixed portfolio. Sandmo's attempt (1969) to answer this question was an exploratory first step. Using a general utility function, $U\left(C_{1}, C_{2}\right)$, he found that the effects of taxation are difficult to evaluate when the return on the riskless 
investment is non-zero. This paper is a further development in this direction in the sense that we have used a separable utility function and have obtained more definitive results. ${ }^{3}$ Further, the present analysis also allows us to examine the effects of taxation on intertemporal consumption decisions under uncertainty.

One other way, in which the present approach differs from those of the singleperiod analysis, is related to the nature of the uncertainty involved. The singleperiod analysis can be interpreted as being concerned with timeless risk prospects, i.e., the uncertainty will be removed before the saving-consumption decision is made, while here we are concerned with temporal risk prospects. In this case the uncertainty about the yield of the risky asset is not going to be removed until the end of the first period, i.e., until after the saving-consumption decision has been made. Dreze and Modigliani (1972) have established that behaviour under temporal uncertainty differs from behaviour under timeless uncertainty, and, hence, it is worthwhile to examine whether taxation changes in a world of temporal risk yield the standard results of pure portfolio theory.

Given this introduction, the rest of the paper proceeds as follows. In section 2 we outline the model to be used throughout the paper, especially noting its assumptions and their behavioural implications. Consumption taxes, both proportional and the progressive linear, ${ }^{4}$ are analysed in the third section, while section 4 discusses proportional and progressive investment income taxes. Section 5 attempts to summarize the main results of the paper. Some background results are outlined in the appendix.

\section{CONSUMPTION AND PORTFOLIO ALLOCATION DECISIONS}

Consumption and portfolio allocation decisions are assumed to satisfy maximisation of the individual's expected lifetime utility. The individual is presumed to live for two periods and the (current) consumption-portfolio allocation decision is made in the first period based on the subjective probability distribution of the outcomes. In the second period the household dissaves, consuming all its capital 
and the exogenous wage incomes. The intertemporal consumption allocation decision can then be stated as

$$
\left.\begin{array}{cc}
\max & E\left\{F\left(C_{1}, C_{2}\right)\right\}=V\left(C_{1}\right)+E U\left(C_{2}\right), \\
\text { s.t } & C_{1}=Y_{1}-a-m, \\
& C_{2}=Y_{2}+a(1+X)+m(1+r),
\end{array}\right\}
$$

where both $\mathrm{V}$ and $\mathrm{U}$ are assumed to be twice continuously differentiable with positive and diminishing marginal utilities, thus guaranteeing risk-aversion and a diminishing marginal rate of substitution between present and future consumption prospects. The notation is as follows: $C_{1}$ and $C_{2}$ are respectively current and future consumption, $\mathrm{Y}_{1}$ and $\mathrm{Y}_{2}$ are the non-asset incomes received in the first and the second periods, while $\underline{a}$ and $\underline{m}$ are the amounts allocated to the risky and the safe assets respectively with $X$ (a random variable) and $\underline{r}$ as their respective rates of return. ${ }^{5}$ We shall also examine in detail the specific case:

$$
F\left(C_{1}, C_{2}\right)=\log C_{1}+(1-\delta) \log C_{2},
$$

and $0<\delta<1$ is a pure time discount factor.

The investor's problem involves choosing $\left\{\mathrm{C}_{1}, \mathrm{C}_{2}, \mathrm{a}, \mathrm{m}\right\}$. Combining the constraints and substituting for $\mathrm{C}_{2}$ in the utility function, we can eliminate the constraints and restate the problem as a two-good, two-period problem:

$$
\max _{\left\{\mathrm{C}_{1}, \mathrm{a}\right\}} \mathrm{V}\left(\mathrm{C}_{1}\right)+\mathrm{E}\left\{\mathrm{U}\left(\mathrm{Y}_{2}+\left(\mathrm{Y}_{1}-\mathrm{C}_{1}\right)(1+\mathrm{r})+\mathrm{a}(\mathrm{X}-\mathrm{r})\right)\right\}
$$

The necessary conditions for the existence of an interior maximum are given by

$$
\begin{gathered}
\mathrm{V}^{\prime}\left(\mathrm{C}_{1}\right)-(1+\mathrm{r}) \mathrm{E}\left\{\mathrm{U}^{\prime}\left(\mathrm{C}_{2}\right)\right\}=0 ; \\
\mathrm{E}\left\{\mathrm{U}^{\prime}\left(\mathrm{C}_{2}\right)(\mathrm{X}-\mathrm{r})\right\}=0 .
\end{gathered}
$$

Since we have assumed strict concavity of both $V\left(C_{1}\right)$ and $U\left(C_{2}\right)$ these are also sufficient conditions for a utility maximum. We may interpret them as follows:

(a) The first says that at an optimum, the marginal rate of time-preference $\left(\left[\mathrm{V}^{\prime}\left(\mathrm{C}_{1}\right) / \mathrm{E}\left\{\mathrm{U}^{\prime}\left(\mathrm{C}_{2}\right)\right\}\right]-1\right)$ equals the rate of return on the safe asset; this corresponds to Fisher's rule for optimisation over time (see Fisher (1930)). 
(b) The second condition says that the expected marginal utility of a unit of investment in each asset is equalised at the optimum, i.e., $E\left\{U^{\prime}\left(C_{2}\right) X\right\}=E\left\{U^{\prime}\left(C_{2}\right) r\right\}$. This is the usual interpretation of a portfolio equilibrium in a single-period framework.

It must be emphasized that additive separability of the utility function is a rather strong assumption. However, this simplifies the analysis considerably by allowing a straight-forward extension of the Arrow-Pratt risk-aversion functions. 6 Clearly, in the context of the utility function in $(2-1)$, the measure of absolute risk-aversion is

$$
A\left(C_{2}\right)=-\left[U^{\prime \prime}\left(C_{2}\right) / U^{\prime}\left(C_{2}\right)\right],
$$

and the corresponding measure of relative risk-aversion is

$$
R\left(C_{2}\right)=-\left[\left\{U^{\prime \prime}\left(C_{2}\right) C_{2}\right\} / U^{\prime}\left(C_{2}\right)\right] \text {. }
$$

This simplification, in turn, gives us the following important results:

(a) If absolute risk-aversion is decreasing the risky asset is superior, 1.e., $\partial \mathrm{a} / \partial \mathrm{Y}_{1}>0$

(b) If absolute risk-aversion is decreasing and relative risk-aversion is non-decreasing,

for $\mathrm{H}>0$, it is both necessary and sufficient that $0<\partial \mathrm{C}_{1} / \partial \mathrm{Y}_{1}<1$, i.e.,

$\mathrm{H}>0 \Leftrightarrow 0<\partial \mathrm{C}_{1} / \partial \mathrm{Y}_{1}<1$, where the Hessian determinant $\mathrm{H}$ is given by the appropriate second-order conditions of the problem $(2-3)$.

These results follow from the additivity of the utility function and the proofs are omitted.

To conclude this section, we note that in the context of an unrestricted utility function, Dreze and Modigliani (1972) observed that restrictions of the form $0<\partial \mathrm{C}_{1} / \partial \mathrm{Y}_{1}<1$ and $\partial \mathrm{a} / \partial \mathrm{Y}_{1}>0$, although representative of actual behaviour, was ‥ ㄴ. beyond the scope of consistency in their model. Clearly, in the context of an additively separable utility function and given the reasonableness of the risk-aversion hypotheses involved, such requirements are an integral part of consistent behaviour. ${ }^{7}$ 
In particular, the existence of a solution to the investor's problem is intimately related to the restriction that $0<\partial c_{1} / \partial Y_{1}<1$.

In this section we analyse the effects of both proportional and progressive consumption tax on saving and risk-taking. The progressive tax schedule, as already indicated, is linear with a marginal tax rate $t$ which applies both above and below a constant exemption level $\underline{\mathrm{K}}$. By setting $\mathrm{K}=0$ we also obtain propositions regarding a flat rate proportional tax.

Linearly progressive taxation of consumption implies the following budget constraints for the individual:

$$
\begin{aligned}
& C_{1}=(1-t)\left(Y_{1}-a-m\right)+K t ; \\
& C_{2}=(1-t)\left[Y_{2}+a(1+X)+m(1+x)\right]+K t .
\end{aligned}
$$

Or, simplifying

$$
C_{2}=\left[(1-t)\left\{Y_{2}+Y_{1}(1+r)+a(X-r)\right\}-C_{1}(1+r)+K t(2+r)\right] .
$$

The problem

$$
\max _{\left\{C_{1}, a\right\}} V\left(C_{1}\right)+E\left\{U\left(C_{2}\right)\right\}
$$

where $C_{2}$ is given by $(3-1)$ is characterised by the following necessary and sufficient conditions:

$$
\begin{aligned}
& V^{\prime}\left(C_{1}\right)-(1+r) E\left\{U^{\prime}\left(C_{2}\right)\right\}=0 ; \\
& (1-t) E\left\{U^{\prime}\left(C_{2}\right)(X-r)\right\}=0 .
\end{aligned}
$$

The effects of a change in $\underline{t}$ on the investor's saving and risk-taking behaviour are given by:

$$
\begin{aligned}
& \frac{\partial C_{1}}{\partial t}=-\left(\frac{1}{1-t}\right)\left\{\left[Y_{1}+Y_{2}(1+r)^{-1}\right]-K\left[1+(1+r)^{-1}\right]\right\} \frac{\partial C_{1}}{\partial Y_{1}} \\
& \frac{\partial a}{\partial t}=\left(\frac{a}{1-t}\right)\left[1-\left\{Y_{1}+Y_{2}(1+r)^{-1}\right\} \frac{1}{a} \frac{\partial a}{\partial Y_{1}}\right]+\left(\frac{2 K}{1-t}\right) \frac{\partial a}{\partial Y_{1}}
\end{aligned}
$$


Case 1: Proportional Consumption Tax $(\mathrm{K}=0)$

Clearly, for $\mathrm{k}=0$ and where both current consumption and risk-taking are superior, ${ }^{8}$ both current consumption and private risk-taking ${ }^{9}$ are reduced by a proportional consumption tax. Total risk-taking (measured by a), however, would increase, remain constant or decrease as the elasticity of the demand for the risky asset with respect to the present value of non-asset wealth is smaller than, equal to or greater than unity. These results are not difficult to interpret: A proportional consumption tax, being equivalent to a tax on wealth, simply reduces current consumption by generating a simple income effect. However, given the capital risk, it also generates a substitution effect encouraging risk-taking (see equation (3-6)), 1.e.,

$$
0<\left(\frac{a}{1-t}\right)=\frac{\partial a}{\partial t} \mid E\left\{F\left(C_{1}, C_{2}\right)\right\}=\text { constant }
$$

This is due to the fact that although the substitution effect leaves current consumption and hence saving $(\mathrm{a}+\mathrm{m})$ unchanged, the tax reduces the probability of large gains and, due to loss offset provisions, the probability of large losses in future consumption; consequently households allocate relatively more of their portfolio to the risky asset so as to maintain the former level of expected utility. However, the Income effect, as usual, tends to reduce risk-taking.

Further, given the appended discussion on risk-aversion and income elasticities (section A.1), we can formally interpret the effect on risk-taking as follows: An increase in the proportional consumption tax

(a) stimulates risk-taking where absolute risk-aversion is decreasing, relative risk-aversion is increasing and the income elasticity of consumption is at least as great as that of the risky asset demand;

(b) has no effect on risk-taking where relative risk-aversion is constant and the income elasticity of consumption equals that of the risky asset demand; ${ }^{10}$.

(c) discourages risk-taking where relative risk-aversion is constant (decreasing) and the income elasticity of consumption is smaller (no larger) than that of the risky asset demand. 
Case 2: Progressive Consumption Tax $(K>0)$

In this case we have additional income effects generated by the lump-sum exemption parameter. From (3-5) we observe that given $\partial \mathrm{C}_{1} / \partial \mathrm{Y}_{1}>0$,

$$
\frac{\partial C_{1}}{\partial t} \leq 0 \text { as } K \stackrel{S}{>}\left\{\frac{Y_{1}+Y_{2}(1+x)^{-1}}{1+(1+r)^{-1}}\right\} \text {; }
$$

i.e., as $\mathrm{K} \lesseqgtr$ the equivalent "permanent income stream". Also note that if there is no investment in the risky asset, the individual is a net recipient if $\mathrm{K}$ exceeds his permanent income, and for $\mathrm{K}$ equal to his permanent income, he is not affected by the taxation policy. The possibility of a stimulatory effect on current consumption is clearly an implication of a negative consumption tax and, hence, is not surprising. We have, therefore, shown that: Where consumption is superior, 11 1inearly progressive taxation of consumption decreases, leaves unchanged or increases current consumption where the equivalent permanent income stream is greater than, equal to or smaller than the exemp$\vdots \quad$ tion level.

Given the appended discussion (section A.1), we may interpret (3-6) as follows: An increase in the marginal tax rate in a system of progressive linear taxation of consumption stimulates risk-taking where (a) absolute risk-aversion is decreasing, relative risk-aversion is non-decreasing and the income elasticity of consumption is at least as great as that of the risky asset demand; or, alternatively, where (b) relative risk-aversion is decreasing, the marginal tax rate is at most $50 \%$ and the income elasticity of consumption is no larger than that of the risky asset demand. ${ }^{12}$ 4. EFFECTS OF AN INVESTMENT INCOME TAX

In this section we analyse the effects of both proportional and progressive investment income taxes on saving and risk-taking behaviour. As in section 3 we set up the general problem first, and then discuss the alternative taxes. The appropriate constraints for a progressive linear tax on investment income are:

$$
\left.\begin{array}{l}
c_{1}=\left(Y_{1}-a-m\right) \\
c_{2}=\left\{Y_{2}+a(1+X)+m(1+r)-t[a X+m r-K]\right\}
\end{array}\right\},
$$




\section{$-8-$}

or, $\quad C_{2}=\left[Y_{2}+\left(Y_{1}-C_{1}\right)+K t-(1-t)\left\{\left(Y_{1}-C_{1}\right) r+a(X-r)\right\}\right], \quad \ldots(4-1)$

where $t$ is now interpreted as the marginal investment income tax rate and $K$ is the exemption. An intertemporal equilibrium of the investor's allocation problem (3-2) subject to $(4-1)$ is described by the following equations:

$$
\begin{aligned}
& V^{\prime}\left(C_{1}\right)-\left(r^{*}\right) E\left\{U^{\prime}\left(C_{2}\right)\right\}=0 ; \\
& (1-t) E\left\{U^{\prime}\left(C_{2}\right)(X-E)\right\}=0 ;
\end{aligned}
$$

where $r^{*} \equiv[1+r(1-t)]$. As before, we obtain

$$
\begin{aligned}
& \frac{\partial c_{1}}{\partial t}=\left(\frac{r C_{1}}{r^{*}}\right)\left[1+\frac{V^{\prime}\left(c_{1}\right)}{V^{\prime \prime}\left(c_{1}\right) C_{1}}\right] \frac{\partial C_{1}}{\partial Y_{1}}-\left(\frac{r C_{1}}{r^{*}}\right)\left[\frac{V^{\prime}\left(C_{1}\right)}{V^{\prime \prime}\left(c_{1}\right) C_{1}}+\frac{Y_{1}}{c_{1}} \frac{\partial c_{1}}{\partial Y_{1}}\right] \\
& +\left(\frac{K}{r^{*}}\right) \frac{\partial C_{1}}{\partial Y_{1}} \\
& \frac{\partial a}{\partial t}=\left(\frac{a}{1-t}\right)\left[1+\frac{r(1-t)}{r^{*}}\left(\frac{Y_{1}}{a} \frac{\partial a}{\partial Y_{1}}\right)\right]+\left(\frac{r C_{1}}{r^{*}}\right)\left[1+\frac{V^{\prime}\left(C_{1}\right)}{V^{\prime \prime}\left(C_{1}\right) C_{1}}\right] \frac{\partial a}{\partial Y_{1}} \\
& +\left(\frac{\mathrm{K}}{\mathrm{r}^{*}}\right) \frac{\partial \mathrm{a}}{\partial \mathrm{Y}_{1}}
\end{aligned}
$$

\section{Case 1: Proportional Investment Income Tax $(\mathrm{K}=0)$}

From equations $(4-4)$ and (4-5) we note that where the rate of return on the riskless investment is zero (which in the present context implies a zero marginal rate of time preference), the effect of a proportional investment income tax is to leave current consumption unchanged and to increase (tota1) risk-taking. 13 Private risk-taking, however, remains unchanged. Under logarithmic preferences of the type $(2-2)$, the above results reduce to (since $\left\{V^{\prime \prime}\left(C_{1}\right) C_{1}\right\} / V^{\prime}\left(C_{1}\right)=-1$ )

$$
\begin{aligned}
& \left.\frac{\partial C_{1}}{\partial t}\right|_{K=0}=\left(\frac{r C_{1}}{r^{*}}\right)\left[1-\frac{Y_{1}}{C_{1}} \frac{\partial C_{1}}{\partial Y_{1}}\right] ; \\
& \left.\frac{\partial a}{\partial t}\right|_{K=0}=\left(\frac{a}{1-t}\right)\left[1+\frac{r(1-t)}{r^{*}}\left(\frac{Y_{1}}{a} \frac{\partial a}{\partial Y_{1}}\right)\right] .
\end{aligned}
$$


We therefore obtain the following: For investors whose preferences can be described by a logarithmic utility function, an increase in the proportional tax on investment income will reduce, leave unchanged or increase current consumption as the income elasticity of consumption is greater than, equal to or smaller than unity; this tax will also encourage risk-taking if the income elasticity of demand for the risky asset is at most unity. Private risk-taking will however decrease.

Although for an income elasticity of the risky asset demand greater than unity risk-taking may decrease, it does not seem very likely given reasonable magnitudes of $\underline{t}$ and $\underline{r} .^{14}$ It is interesting to observe that the intertemporal effects of an investment income tax on risk-taking for logarithmic preferences are identical to those obtained for a general utility function in a single-period framework (e.g., see Stiglitz (1969a)).

One other special case may be of interest. This is where the individual, before the tax change, is neither a borrower nor a saver, $i_{. e .,} C_{1}=Y_{1}$. In such a case, it is seen from (4-4) that an increase in the tax rate stimulates current consumption. In a somewhat different context Feldstein and Tsiang (1968) have interpreted such a result to imply that if tax decreases are directed towards low-income groups for whom saving is non-existent or relatively low, a positive stimulus to saving is more likely.

In the general case, however, where the utility function is given by (2-1) and $r \neq 0$, the interpretation of $(4-4)$ and (4-5) together with the appendix results would run as follows: An increase in the proportional tax on investment income (a) discourages current consumption where the investor exhibits non-decreasing relative risk-aversion, consumes a constant fraction of income (i.e., $c_{1}=k Y$ ) and has an elasticity of marginal utility of consumption at least as great as unity; ${ }^{15}$ (b) encourages risk-taking where the investor exhibits decreasing absolute risk-aversion, invests a non-increasing proportion of income in the risky asset as income increases and has an elasticity of marginal utility of consumption at least as great as unity. 16 
The difficulty in obtaining any straight-forward results in the case of an investment income tax can be intuitively explained as follows. A tax on investment income is effectively a tax on future consumption and hence the substitution effect works in favour of current consumption and risk-taking. 17 However, these stimulatory effects may or may not be outweighed by the income effects.

Case 2: Progressive Investment Income $\operatorname{Tax}(K>0)$

From $(4-4)$ and $(4-5)$ we observe that where the rate of return on the riskless investment is zero, unlike the proportional investment income tax, current consumption and private (and social) risk-taking are both increased by progressive linear taxation of investment income. This is easily explained: the lump-sum exemption generates income effects thus stimulating both current consumption and private risk-taking; social risk-taking, however, is increased when this exemption generated income effect reinforces the positive substitution effect. This interpretation requires that both current consumption and the risky asset are superior.

In general, however, the results are somewhat difficult to interpret. For the case of logarithmic preferences the first term of (4-4) and the second term of (4-5) drop out. Thus we obtain: for investors with logarithmic preferences, linear1y progressive taxation of investment income increases current consumption (or, risk-taking) where the individual allocates a non-increasing proportion of income to current consumption (or, to the risky asset) as income increases.

There is one other case where the effect of the tax on risk-taking is unambiguous. (This does not require the assumption of logarithmic preferences; see equation (4-5).) Progressive linear taxation of investment income encourages risk-taking where the investor exhibits decreasing absolute risk-aversion, invests a non-increasing proportion of income in the risky asset as income increases and has an elasticity of marginal utility of consumption at least as great as unity. ${ }^{18}$ 


\section{SUMMARY AND CONCLUSION}

The main results of the paper can conveniently be summarised in the following tables (5.1 and 5.2). From Table 5.1 it is clear that the effects of both proportional and progressive taxation of consumption are to discourage current consumption for typical individuals (i.e., we would expect the exemption level to be smaller than permanent income). These results, however, do not involve any intertemporal substitution of consumption and are pure income effects. On the other hand, the effect of an investment income tax (proportional or progressive) on consumption is less straightforward. Specifically, this tax--essentially on future consumption-encourages a substitution in favour of current consumption, but the income effects render the total effect somewhat ambiguous. Nevertheless, if we regard an income elasticity of consumption of less than or equal to unity as typical, this tax stimulates current consumption (this, however, requires logarithmic preferences).

Apart from the ease of zero rate of return on riskless investment, the results regarding total risk-taking are considerably more ambiguous. Consumption and investment income taxes, although they encourage a substitution in favour of risk-taking, are not easy to interpret. Alternative sets of sufficient conditions for these results to be unambiguous are detailed in Table 5.2.

The main conclusion, therefore, is that while hypotheses on risk-aversion functions are more or less adequate in determining the effects of taxation on risktaking in single-period analysis, they are no longer adequate in an intertemporal context. In particular, we frequently require the knowledge of various income elasticities (and their relative magnitudes) in addition to assumptions on risk-aversion. However, these results can still be regarded as meaningful in that, at least in principle, the magnitudes of these income elasticities can be determined. 
Table 5.1 Effects of Taxation on Current Consumption

Type of Taxation

\begin{tabular}{|c|c|c|}
\hline $\begin{array}{c}\text { Type of tax } \\
\text { Base }\end{array}$ & Proportional & Progressive \\
\hline Consumption & if $\frac{\partial \mathrm{C}_{1}}{\partial \mathrm{Y}_{1}}>0$ & $\begin{array}{l}\text { POS, ZERO, OR NEG } \\
\text { as } \mathrm{K} \gtreqless\left(\frac{\mathrm{Y}_{1}+\mathrm{Y}_{2}(1+\mathrm{r})^{-1}}{1+(1+\mathrm{r})^{-1}}\right) \text {. }\end{array}$ \\
\hline $\begin{array}{l}\text { Investment } \\
\text { Income }\end{array}$ & $\begin{array}{l}\text { (a) ZERO if } r=0 \text {; or } \\
\text { (b) } \text { POS, ZERO, OR NEG } \\
\text { as } \frac{Y_{1}}{\mathrm{C}_{1}} \frac{\partial \mathrm{C}_{1}}{\partial \mathrm{Y}_{1}}>1 \\
\text { and the utility is } \\
\text { logarithmic; or } \\
\text { (c) NEGATIVE if } \\
\text { (i) } \partial \mathrm{R}\left(\mathrm{C}_{2}\right) / \partial \mathrm{C}_{2} \geq 0, \\
\text { (ii) }\left(\mathrm{Y}_{1} / \mathrm{C}_{1}\right)\left(\partial \mathrm{C}_{1} / \partial \mathrm{Y}_{1}\right)=1 \\
\text { and, } \\
\text { (iii) }\left[-\mathrm{V}^{\prime \prime}\left(\mathrm{C}_{1}\right) \mathrm{C}_{1} / \mathrm{V}^{\prime}\left(\mathrm{C}_{1}\right)\right]\end{array}$ & $\begin{array}{l}\text { if (a) } r=0 \text { and } \partial \mathrm{c}_{1} / \partial \mathrm{Y}_{1}>0 \text {; } \\
\text { or } \\
\text { (b) }\left(\mathrm{Y}_{1} / \mathrm{C}_{1}\right)\left(\partial \mathrm{C}_{1} / \partial \mathrm{Y}_{1}\right) \leq 1 \\
\text { and the utility is } \\
\text { logarithmic. }\end{array}$ \\
\hline
\end{tabular}


Table 5.2 Effects of Taxation on Total (Social) Risk-Taking

Type of Taxation

\begin{tabular}{|c|c|c|}
\hline $\begin{array}{c}\text { Type of tax } \\
\text { Base } \\
\end{array}$ & Proportional & Progressive \\
\hline Consumption & 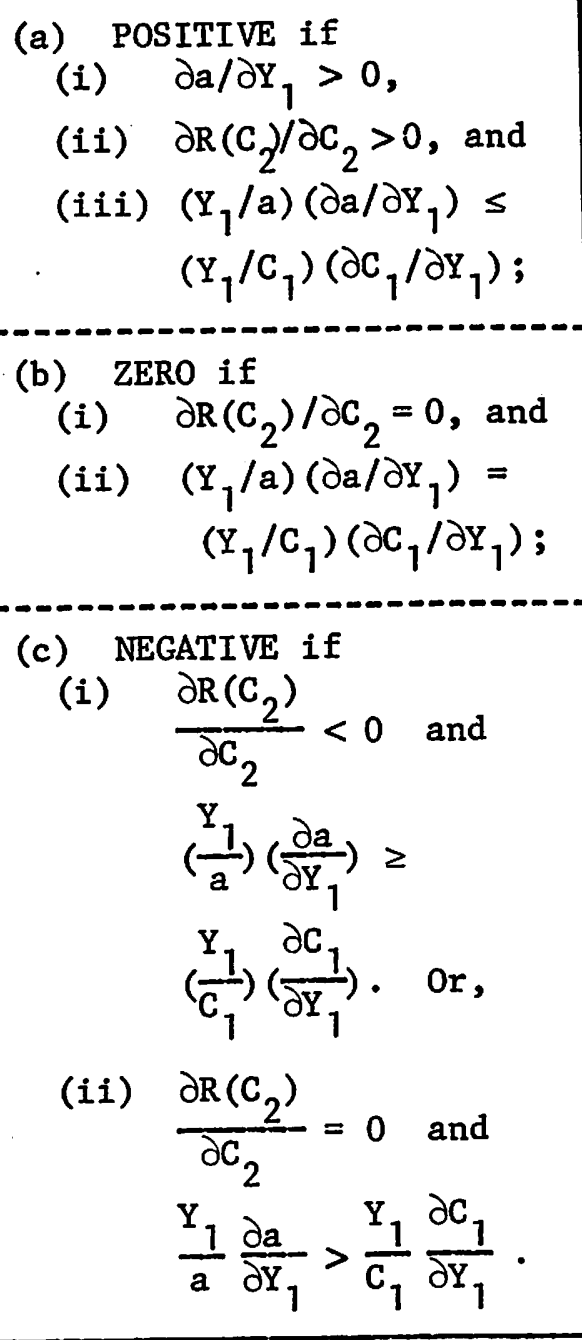 & 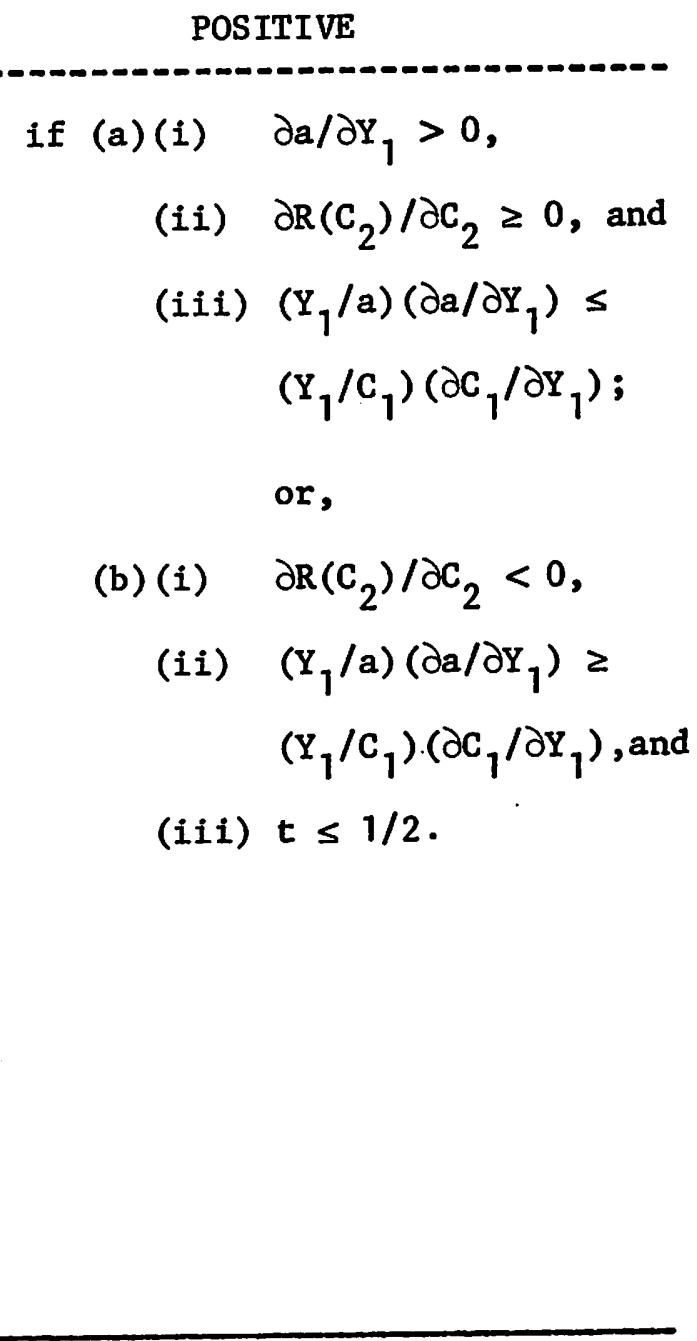 \\
\hline $\begin{array}{l}\text { Investment } \\
\text { Income }\end{array}$ & $\begin{array}{l}\text { if (a) } \mathrm{r}=0 ; \text { or } \\
\text { (b) }\left(\mathrm{Y}_{1} / \mathrm{a}\right)\left(\partial \mathrm{a} / \partial \mathrm{Y}_{1}\right) \leq 1 \\
\text { and the utility is } \\
\text { logarithmic; or } \\
\text { (c) } \begin{array}{l}\text { (i) } \partial a / \partial \mathrm{Y}_{1}>0, \\
\text { (ii) }\left(\mathrm{Y}_{1} / \mathrm{a}\right)\left(\partial a / \partial \mathrm{Y}_{1}\right) \\
\leq 1, \text { and } \\
\text { (iii) }-\left[\mathrm{V}^{\prime \prime}\left(\mathrm{C}_{1}\right) \mathrm{C}_{1} / \mathrm{V}^{\prime}\right. \\
\left.\left(\mathrm{C}_{1}\right)\right] \geq 1\end{array}\end{array}$ & $\begin{array}{l}\text { if (a) } \mathrm{r}=0 \text { and } \partial \mathrm{a} / \partial \mathrm{Y}_{1}>0 \text {; or } \\
\text { (b) }\left(\mathrm{Y}_{1} / \mathrm{a}\right)\left(\partial \mathrm{a} / \partial \mathrm{Y}_{1}\right) \leq 1 \text { and } \\
\text { the utility is } \\
\text { logarithmic; } \\
\text { (c) (i) } \partial \mathrm{a} / \partial \mathrm{Y}_{1}>0, \\
\text { (ii) }\left(\mathrm{Y}_{1} / \mathrm{a}\right)\left(\partial a / \partial \mathrm{Y}_{1}\right) \\
\leq 1, \text { and } \\
\text { (iii) }-\left[\mathrm{V}^{\prime \prime}\left(\mathrm{C}_{1}\right) \mathrm{C}_{1} / \mathrm{V}^{\prime}\left(\mathrm{C}_{1}\right)\right] \\
\geq 1 .\end{array}$ \\
\hline
\end{tabular}




\section{APPENDIX}

\section{A.1 Relative Risk-Aversion and Income Elasticities}

In this section we derive some basic results on the relationship between income elasticities and hypotheses on relative risk-aversion. First let us note the following results on risk-aversion:

Lemma A.1 (a) In the context of the model described in section 2 of the text, $\mathrm{E}\left\{\mathrm{U}^{\prime \prime}\left(\mathrm{C}_{2}\right)(\mathrm{X}-\mathrm{r})\right\}<^{2} 0$ as absolute risk-aversion, $\mathrm{A}\left(\mathrm{C}_{2}\right)$, decreases, remains constant, or increases as $\mathrm{C}_{2}$ increases;

Lemma A.1(b) Under the conditions of lemma $A .1(a), E\left\{U^{\prime \prime}\left(C_{2}\right)(X-r) C_{2}\right\} \leq 0$ as relative risk-aversion, $\mathrm{R}\left(\mathrm{C}_{2}\right)$, increases, remains constant, or decreases as $\mathrm{C}_{2}$ increases. The proofs, being similar to the ones given by Arrow (1971), are omitted.

Using the definition of $C_{2}$ as given by $(2-3)$, lemma $A .1(b)$ states that

$$
\begin{aligned}
& {\left[\mathrm{Y}_{2}+\mathrm{Y}_{1}(1+r)\right] \mathrm{E}\left\{\mathrm{U}^{\prime \prime}\left(\mathrm{C}_{2}\right)(\mathrm{X}-\mathrm{r})\right\}+\mathrm{aE}\left\{\mathrm{U}^{\prime \prime}\left(\mathrm{C}_{2}\right)(\mathrm{X}-\mathrm{r})^{2}\right\}} \\
& \quad \lessgtr \mathrm{C}_{1}(1+r) E\left\{U^{\prime \prime}\left(\mathrm{C}_{2}\right)(\mathrm{X}-\mathrm{r})\right\} \text { as } \partial \mathrm{R}\left(\mathrm{C}_{2}\right) / \partial \mathrm{C}_{2} \gtreqless 0 .
\end{aligned}
$$

In view of the expressions for the terms $\partial c_{1} / \partial y_{1}$ and $\partial a / \partial y_{1}$, as obtainable from the equations $(2-4)$ and $(2-5)$ of the text, and in view of lemma A.1(a), the above reduces to

$$
\begin{gathered}
\left(\frac{1}{a} \frac{\partial \mathrm{a}}{\partial \mathrm{Y}_{1}}\right)\left\{\mathrm{Y}_{1}+\mathrm{Y}_{2}(1+x)^{-1}\right\} \lessgtr\left\{1+\frac{\mathrm{C}_{1}}{\mathrm{a}} \frac{\partial \mathrm{a}}{\partial \mathrm{Y}_{1}}-\frac{\partial \mathrm{C}_{1}}{\partial \mathrm{Y}_{1}}\right\} \\
\text { as } \partial \mathrm{R}\left(\mathrm{C}_{2}\right) / \partial \mathrm{C}_{2} \gtreqless 0 \text { and } \partial \mathrm{A}_{2}\left(\mathrm{C}_{2}\right) / \partial \mathrm{C}_{2}<0 .
\end{gathered}
$$

We can state this result as follows:

(a) where $A\left(C_{2}\right)$ is decreasing and $R\left(C_{2}\right)$ is increasing

$$
\left(\frac{1}{a} \frac{\partial a}{\partial Y_{1}}\right)\left\{Y_{1}+Y_{2}(1+r)^{-1}\right\}<1 \text { if }\left(\frac{Y_{1}}{a} \frac{\partial a}{\partial Y_{1}}\right) \leq\left(\frac{Y_{1}}{C_{1}} \frac{\partial C_{1}}{\partial Y_{1}}\right) \text {; }
$$

(b) where $R\left(C_{2}\right)$ is constant ${ }^{19}$

$$
\left(\frac{1}{a} \frac{\partial a}{\partial Y_{1}}\right)\left\{Y_{1}+Y_{2}(1+r)^{-1}\right\}=1 \text { iff }\left(\frac{Y_{1}}{a} \frac{\partial a}{\partial Y_{1}}\right)=\left(\frac{Y_{1}}{C_{1}} \frac{\partial C_{1}}{\partial Y_{1}}\right) ;
$$


(c) where $R\left(C_{2}\right)$ is decreasing

$$
\left(\frac{1}{a} \frac{\partial a}{\partial Y_{1}}\right)\left\{Y_{1}+Y_{2}(1+r)^{-1}\right\}>1 \text { if }\left(\frac{Y_{1}}{a} \frac{\partial a}{\partial Y_{1}}\right) \geq\left(\frac{Y_{1}}{C_{1}} \frac{\partial C_{1}}{\partial Y_{1}}\right) \text {. }
$$

Also note that for constant $R\left(C_{2}\right),\left(\frac{1}{a} \frac{\partial a}{\partial Y_{1}}\right)\left\{Y_{1}+Y_{2}(1+r)^{-1}\right\}>1$ if

$$
\left(\frac{\mathrm{Y}_{1}}{\mathrm{a}} \frac{\partial \mathrm{a}}{\partial \mathrm{Y}_{1}}\right)>\left(\frac{\mathrm{Y}_{1}}{\mathrm{C}_{1}} \frac{\partial \mathrm{C}_{1}}{\partial \mathrm{Y}_{1}}\right)
$$

In the text we have used such results in order to interpret the effects of consumption taxes (both proportional and progressive). We therefore ask how the interpretation of $(\mathrm{A}-2)$ is modified in the presence of taxation.

Proportional Consumption Tax. In this case the inequality (A-2) is modified into

$$
\left(\frac{1}{a} \frac{\partial a}{\partial Y_{1}}\right)\left\{Y_{1}+Y_{2}(1+r)^{-1}\right\} \lessgtr\left[1+\left(\frac{1}{1-t}\right)\left\{\frac{C_{1}}{a} \frac{\partial a}{\partial Y_{1}}-\frac{\partial C_{1}}{\partial Y_{1}}\right\}\right],
$$

where $\partial a / \partial \mathrm{Y}_{1}, \partial \mathrm{c}_{1} / \partial \mathrm{Y}_{1}$ are obtainable from $(3-3)$ and $(3-4)$ of the text and $\mathrm{c}_{2}$ is defined by $(3-1)$ with $\mathrm{K}=0$. Comparing $(A-3)$ to $(A-2)$ it is evident that all the above results are valid for a proportional consumption tax.

Progressive Consumption Tax. Proceeding in the above manner we obtain

$$
\begin{aligned}
\left(\frac{1}{a} \frac{\partial a}{\partial Y_{1}}\right)\left\{Y_{1}+Y_{2}(1+r)^{-1}\right\} & +\frac{K t(2+r)}{a(1+r)(1-t)}\left(\frac{\partial a}{\partial Y_{1}}\right) \\
& \lessgtr\left[1+\left(\frac{1}{1-t}\right)\left\{\frac{C_{1}}{a} \frac{\partial a}{\partial Y_{1}}-\frac{\partial C_{1}}{\partial Y_{1}}\right\}\right]
\end{aligned}
$$

instead of $(A-3)$. In view of the second term on the 1.h.s. of the inequality, the preceding results are modified:

In the presence of a linearly progressive tax on consumption,

$$
\left(\frac{1}{a} \frac{\partial a}{\partial Y_{1}}\right)\left\{Y_{1}+Y_{2}(1+r)^{-1}\right\}<1 \text { if }\left(\frac{Y_{1}}{a} \frac{\partial a}{\partial Y_{1}}\right) \leq\left(\frac{Y_{1}}{C_{1}} \frac{\partial C_{1}}{\partial Y_{1}}\right)
$$

where $A\left(C_{2}\right)$ is decreasing and $R\left(C_{2}\right)$ is non-decreasing. Also note that for 
decreasing $R\left(C_{2}\right)$ we have

$$
\begin{gathered}
\frac{\mathrm{Kt}(2+\mathrm{r})}{(1+\mathrm{r})(1-\mathrm{t})}\left(\frac{1}{\mathrm{a}} \frac{\partial \mathrm{a}}{\partial \mathrm{Y}_{1}}\right)>\left[1-\left(\frac{1}{\mathrm{a}} \frac{\partial \mathrm{a}}{\partial \mathrm{Y}_{1}}\right)\left\{\mathrm{Y}_{1}+\mathrm{Y}_{2}(1+\mathrm{r})^{-1}\right\}\right] \\
\text { if }\left(\frac{\mathrm{Y}_{1}}{\mathrm{a}} \frac{\partial \mathrm{a}}{\partial \mathrm{Y}_{1}}\right) \geq\left(\frac{\mathrm{Y}_{1}}{\mathrm{C}_{1}} \frac{\partial \mathrm{C}_{1}}{\partial \mathrm{Y}_{1}}\right) .
\end{gathered}
$$

\section{A.2 Feldstein on Taxation and Risk-Taking}

In the context of a two-period model, Feldstein (1969) assumes that the second period uncertain income $(W)$ is, in the absence of taxation, entirely consumed in that period. To avoid "the complications of dynamic analysis", he takes this income as the appropriate tax base. He further restricts the utility function such that it implies constant relative risk-aversion and has constant elasticity. We, therefore, have $U(C)=\alpha C^{\beta}$, where $\alpha, \beta$ are arbitrary constants. In the absence of taxation $(C=W)$, expected utility maximisation requires

$$
\alpha \int W^{\beta_{f_{i}}}(W) d W>\alpha \int W^{\beta_{f}}{ }_{j}(W) d W
$$

for state-i to be preferred to state-j. Clearly, a proportional tax on $\mathrm{W}$ leaves the preference ordering of the distributions unchanged. Feldstein, therefore, concludes that a proportional tax has no effect on risk-taking.

The fact that the above result depends crucially on the tax base considered can be seen most easily by reinterpreting $W$ as final wealth such that $W=W_{0}+Y$, where $\mathrm{W}_{\mathrm{O}}$ is initial wealth and $\mathrm{Y}$ is the uncertain income. Evidently, a proportional wealth (consumption) tax has no effect on risk-taking, while an income tax would, in general, have some effects.

The effect of a consumption tax obtained in an explicit intertemporal context (section 3 of the text) brings out further limitations of Feldstein's"counter-example". It is seen, contrary to Feldstein, that the assumption of constant relative riskaversion is by no means sufficient for a proportional consumption tax to leave risktaking unchanged; income elasticities are relevant. More specifically, it has been shown that under constant relative risk-aversion, risk-taking would be discouraged where the income elasticity of the risky asset demand exceeds that of consumption. 


\section{FOOTNOTES}

*This paper, an earlier version of which was presented at the Public Economics Workshop, University of Essex, July 1973, is based on a chapter of my doctoral dissertation (Ahsan 1974a). I am grateful to Professors S. Ahmad, A. B. Atkinson, W. Birdsa11, D. W. Butterfield, A. L. Robb, A. Sandmo, the , referees and one of the co-editors of this journal for their helpful comments and suggestions.

${ }^{1}$ See, for instance, the survey paper by Allingham (1972) and the references cited therein.

2Flemming (1971), Hahn (1970), Hakansson (1970), Levhari-Srinivasan (1969), Merton (1969) and Rothschild-Stiglitz (1971), among others, have discussed multiperiod (mostly infinite-horizon) models of consumption and portfolio allocation analysing additive utility functions with the discounting of an instantaneous utility function, with the latter being often very restrictive (e.g., exhibiting constant relative risk-aversion). More in the spirit of the present paper are Sandmo (1968, 1969) and Dreze-Modigliani (1972), all of which work in a two-period framework.

${ }^{3}$ Although Flemming (1971) analyses the effects of taxation on portfolio allocation in a continuous time model with infinite horizon, his results--mostly ambiguous--are somewhat difficult to relate to those obtained here since the two models differ in many respects.

${ }^{4}$ The progressive tax schedule considered is a linear tax which has an "exemption level" $\mathrm{K}$ and a marginal rate which applies both above and below $\mathrm{K}$. This structure, apart from being analytically tractable, also captures the generally accepted notion of progression, namely, that the marginal tax rate be greater than the average tax rate. Further letting $\mathrm{K}=0$, would allow propositions regarding a flat rate proportional tax. 
$5_{\text {We restrict } X}$ to 1 ie in the interval $[-1, \infty)$, thus implying limited liability. ${ }^{6}$ See Arrow (1971) and Pratt (1964).

7 The rationale behind the original hypotheses on risk-aversion functions put forward by Arrow (1971)--apart from the criticisms against them (see, for instance, Stiglitz (1969b))--breaks down in an intertemporal context. However, since all our results in the next two sections will be stated in terms of income elasticity of consumption and asset demand, and since these elasticities are in principle observable, our results are not specific with respect to particular risk-aversion hypotheses.

${ }^{8}$ Alternatively, the assumptions of non-decreasing relative risk-aversion and decreasing absolute risk-aversion are sufficient to yield this result.

${ }^{9}$ We follow Atkinson-Stiglitz (forthcoming) and regard $\underline{a(1-t)}$ as an indicator of private risk-taking.

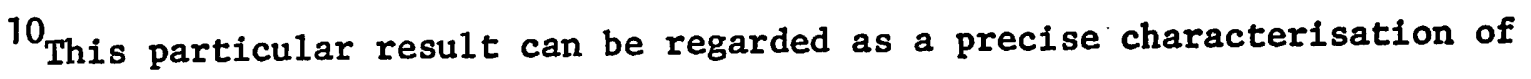
Feldstein's result (1969). Feldstein provided a counter-example to the previous 1iterature by showing that, in the model he considered, a proportional tax has no effect on risk-taking. In the appendix (section A.2) we point out the shortcomings of his approach.

${ }^{11}$ See footnote 8 .

12 This last statement specifies the conditions for $(t / a)(\partial a / \partial t)$ to be positive (see inequality $(A-6)$ of the appendix).

${ }^{13}$ Sandmo (1969) also observes this result in the general model.

${ }^{14}$ For instance, if $r=10 \%$ and $t=50 \%$, this would require a value of the income elasticity of the risky asset greater than 21 for risk-taking to decrease. Also notice that in an intertemporal context, an elasticity greater than unity need not correspond to the hypothesis of decreasing relative risk-aversion (see section $\mathrm{A}-1$ of the appendix). 
${ }^{15}$ Arrow (1971) has shown that the elasticity of marginal utility (e.g., $\left.\left\{-V^{\prime \prime}\left(C_{1}\right) C_{1} / V^{\prime}\left(C_{1}\right)\right\}\right)$ must be in the neighbourhood of unity for $V\left(C_{1}\right)$ to be bounded. - However, he has also pointed out that as $C_{1}$ becomes small boundedness requires that this elasticity must tend to a limit above unity.

${ }^{16}$ See footnote 15

17 Equation (3-7) again denotes the substitution effect in the risk-taking function, while $\left\{-\left(r / r^{*}\right)\left(V^{\prime}\left(C_{1}\right) / V^{\prime \prime}\left(C_{1}\right)\right\}\right.$ is the substitution effect in equation $(4-4)$

${ }^{18}$ See footnote 15

${ }^{19}$ It is impossible to have non-decreasing $A\left(C_{2}\right)$ where $R\left(C_{2}\right)$ is non-increasing. 


\section{REFERENCES}

Ahsan, S. M., 1974a, Taxation and Behaviour Under Uncertainty (Unpublished doctoral dissertation, McMaster University).

Ahsan, S. M., 1974b, Progression and Risk-Taking, Oxford Economic Papers (November, forthcoming).

Ahsan, S. M., 1975, A Note on Capital Gains Exemption and Risk-Taking, Quarterly Journal of Economics (February, forthcoming).

Allingham, M. G., 1972, Risk-Taking and Taxation, Zeitschrift fur Nationa18konomie $32,203-224$.

Arrow, K. J., 1971, Essays in the Theory of Risk-Bearing (Markham, Chicago). Atkinson, A. B. and J. E. Stiglitz, forthcoming, Lectures on Public Finance. Dréze, J. and F. Modigliani, 1972, Consumption Decisions Under Uncertainty, Journal of Economic Theory 5, 308-335.

Feldstein, M. S., 1969, The Effects of Taxation on Risk-Taking, Journal of Political Economy $77,755-764$.

Feldstein, M. S. and S. C. Tsiang, 1968, The Interest Rate, Taxation, and the Personal Savings Incentive, Quarterly Journal of Economics 82, 419-434. Fisher, I., 1930, The Theory of Interest (Macmillan, New York). F1emming, J. S., 1971, Portfolio Choice and Taxation in Continuous Time, unpublished paper.

Hahn, F. H., 1970, Savings and Uncertainty, Review of Economic Studies 37, 21-24. Hakansson, N. H., 1970, Optimal Investment and Consumption Strategies Under Risk For a Class of Utility Functions, Econometrica 38, 587-607.

Levhari, D. and T. N. Srinivasan, 1969, Optimal Savings Under Uncertainty, Review of Economic Studies $36,153-163$.

Merton, R. C., 1969, Lifetime Portfolio Selection Under Uncertainty, Review of Economics and Statistics 51, 247-257. 
Mossin, J., 1968, Taxation and Risk-Taking: An Expected Utility Approach, Economica $35,74-82$.

Pratt, J. W., 1964, Risk-Aversion in the Small and in the Large, Econometrica 32, 122-136.

Rothschild, M. and J. E. Stiglitz, 1971, Increasing Risk II: Its Economic Consequences, Journal of Economic Theory 3, 66-84.

Sandmo, A., 1968, Portfolio Choice in a Theory of Saving, Swedish Journal of Economics 70, 106-122.

Sandmo, A., 1969, Capital Risk, Consumption, and Portfolio Choice, Econometrica 37, 586-599.

Stiglitz, J. E., 1969a, The Effects of Income, Wealth and Capital Gains Taxation on Risk-Taking, Quarterly Journal of Economics 83, 263-283.

Stiglitz, J. E., 1969b, Review of Some Aspects of the Theory of Risk-Bearing, Econometrica $37,742-743$. 